\title{
The Improvement of first Iteration Log Periodic Fractal Koch Antenna with Slot Implementation
}

\author{
N.S.M. Yaziz ${ }^{1}$, M.K.A Rahim ${ }^{2}$, F. Zubir ${ }^{3}$, N.S. Nadzir ${ }^{4}$, R. Dewan ${ }^{5}$, H.A. Majid ${ }^{6}$ \\ 1,2,3,4,5 Advanced RF and Microwave Research Group (ARFMRG), Communication Engineering Department, \\ Faculty of Electrical Engineering, Universiti Teknologi Malaysia, 81310 UTM Johor Bahru, Johor, Malaysia \\ ${ }^{6}$ Research Center for Applied Electromagnetics, Universiti Tun Hussein Onn Malaysia, \\ Parit Raja, Batu Pahat, Johor, Malaysia
}

\begin{tabular}{l}
\hline \hline Article Info \\
\hline Article history: \\
Received Mar 12, 2018 \\
Revised Jun 28, 2018 \\
Accepted Jul 6, 2018 \\
\hline
\end{tabular}

\section{Keyword:}

Fractal Koch geometry

Log periodic antenna

Slotted technique

UHF band

\section{Corresponding Author:}

\begin{abstract}
In this paper, a slotted is introduced at each of the radiating elements on the $1^{\text {st }}$ iteration log periodic fractal Koch antenna (LPFKA). The antenna is designed to testify the appropriate performance at UHF Digital television which operates from $4.0 \mathrm{GHz}$ to $1.0 \mathrm{GHz}$. The dimension of the conventional $0^{\text {th }}$ iteration LPKFA is successfully reduced by $17 \%$ with the implementation of slotted. The results show a good agreement with a stable radiation pattern across the operating bandwidth, stable gain more than $5 \mathrm{dBi}$ and reflection coefficient of below $-10 \mathrm{~dB}$ over the desired frequency range.
\end{abstract}

M.K.A. Rahim,

Communication Engineering Department,

Faculty of Electrical Engineering,

Universiti Teknologi Malaysia,

81310 UTM Johor Bahru, Johor, Malaysia.

Email: mdkanal@utm.my

\section{INTRODUCTION}

Log periodic dipole antenna (LPDA) antenna is used in the radio signal detection and can achieve high directivity with low cross-polarization ratio over a very large frequency range. Such wideband antenna have typically been constructed using the Euclidean radiating elements [1]. Miniaturize concepts are often utilized since in many application the space and weight for microwave circuitary is limited [2].

Digital television (DTV) offers significantly better sound quality and image [3] while improving the spectrum utilization. Several antennas have been designed for Ultra High Frequency (UHF) bands due to the increasing interest in DTV applications [4], [5]. Since the respective wavelength is large which is 400-640 $\mathrm{mm}$, the design for a reduced sized [6] is crucial. Numerous technique is considered to minimize the antenna size such as with the use of metamatrial, co-planar waveguide [7], and fractal geometry [8]-[10].

Fractal [11] is the duplication of the similar geometry shape which is implemented by scaling the geometry shapes. Benoit Mandelbort in 1975 [12] defined a fractal as the method to classify the structure that is difficult to be defined with Euclidean geometry. Koch curve [13], [14] have been widely used with narrowband antenna miniaturization schemes [15].

In this paper, the proposed antenna with fractal Koch geometry [16] and ring slot [17] are design for size miniaturization purpose. The proposed antenna size is reduced by $17 \%$ as compared to the conventional one which is the $0^{\text {th }}$ iteration LPDA. The antenna has been designed by using Computer Simulation Technology (CST) software and fabricated on FR4 Epoxy dielectric substrate with relative permittivity of 5.4 , substrate thickness of $1.6 \mathrm{~mm}$ and $\tan \delta$ of 0.02 . 


\section{ANTENNA DESIGNS}

The proposed log periodic dipole antenna (LPDA) is intended to have a bandwidth of $86 \%$ for $\mathrm{S}_{11}<-10 \mathrm{~dB}$ starting from $0.4 \mathrm{GHz}$ up to $1.0 \mathrm{GHz}$ in order to cover the UHF digital TV application with an average gain of more than $5 \mathrm{dBi}$. The method to apply the fractal Koch geometry on log periodic elements is by dividing an Euclidian dipole of 1 unit length to 4 equal parts, which each of the parts having length of $1 / 4$ unit. The second element is then rotated by $60^{\circ}$ from the horizontal axis while the third one is rotated by $-60^{\circ}$ from the horizontal axis. The first, $1^{\text {st }}$ and the fourth, $4^{\text {th }}$ elements are retained to be in horizontal position. Thus, the total length of the proposed antenna will be the same as the total length of the Euclidian dipole. However, the length in transversal direction from the starting point to the end point of the fractal dipole will be $3 / 4$ of the Euclidian dipole. Figure 1 shows the geometry iteration of the dipole fractal Koch antenna element.

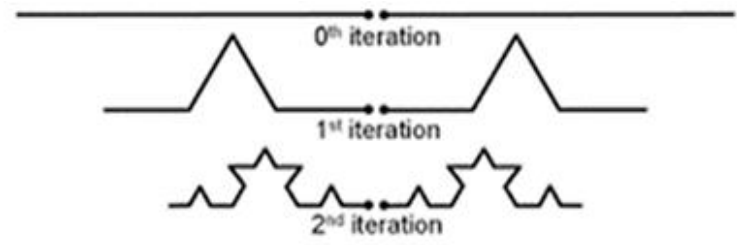

Figure 1. Geometry iteration of dipole fractal Koch antenna element

One of the important parameters in designing the log periodic antenna is the scaling factor $(\tau)$ which is defined as the ratio between two consecutive antenna elements in term of: length $(l)$, and width $(w)$ of antenna elements and the distance between antenna elements $(d)$ expressed in Equation (1) and $n$ is the number of elements [18]. Another important parameters are the spacing factor $(\sigma)$ and gain. The relation between $\tau, \sigma$ and gain is shown in Figure 2 [18].

$$
\tau=\frac{l_{n}}{l_{n+1}}=\frac{w_{n}}{w_{n+1}}=\frac{d_{n}}{d_{n+1}}
$$

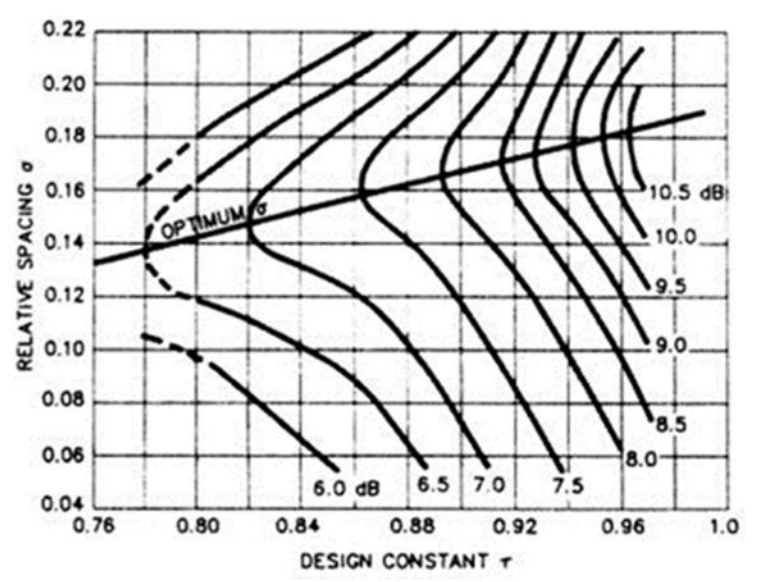

Figure 2. Relation of $\sigma, \tau$ and antenna gain for the log periodic antenna design [18]

By using Equation (1) in [18], the design parameters with scaling factor $(\tau)$ of 0.85 and the spacing factor $(\sigma) 0.15$ are obtained from Figure 2. The number of calculated elements is 9 for each sides. Three different designs which are the $0^{\text {th }}$ iteration, $1^{\text {st }}$ iteration and slotted $1^{\text {st }}$ iteration are shown in Figure 3 . The angle used for the $1^{\text {st }}$ and slotted $1^{\text {st }}$ iteration is $60^{\circ}$.

Table 1 summarizes the percentage of the size reductions achieved for the antennas designs. The size reduction of the $1^{\text {st }}$ iteration with the $0^{\text {th }}$ iteration of the log periodic fractal Koch antenna is relatively about $10 \%$. About $17 \%$ reduction of the antenna size has been achieved using slotted $1^{\text {st }}$ iteration of the fractal Koch technique. Figure 4 shows the fabricated antenna design. 


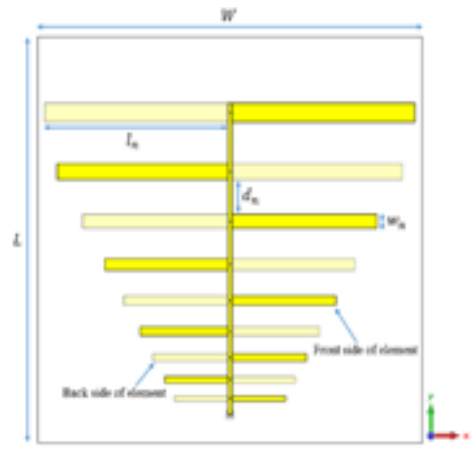

(a)

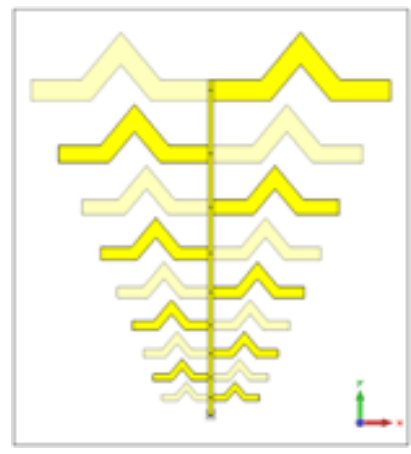

(b)

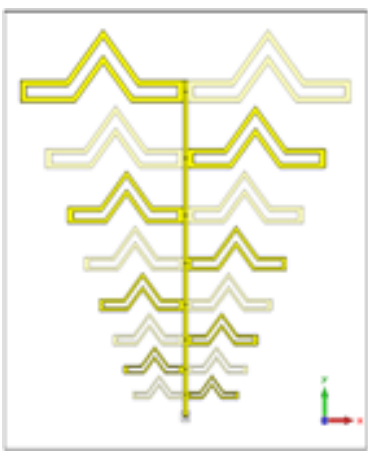

(c)

Figure 3. Configuration of the proposed antenna (a) $0^{\text {th }}$ iteration (b) $1^{\text {st }}$ iteration (c) slotted $1^{\text {st }}$ iteration

Table 1. Percentage of the Size Reduction on the Antenna Design

\begin{tabular}{ccc}
\hline Antenna type & $\begin{array}{c}\text { Dimension } \\
(L \times W \times t)\end{array}$ & $\begin{array}{c}\text { Size of reduction } \\
(\%)\end{array}$ \\
\hline $0^{\text {th }}$ iteration & $290 \times 300 \times 1.6$ & - \\
$1^{\text {st }}$ iteration & $290 \times 270 \times 1.6$ & 10 \\
Slotted $1^{\text {st }}$ iteration & $265 \times 270 \times 1.6$ & 17 \\
\hline
\end{tabular}

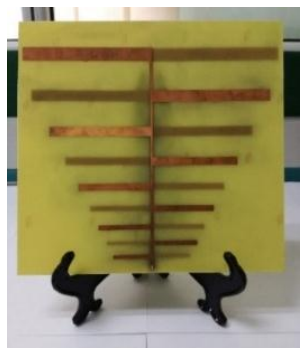

(a)

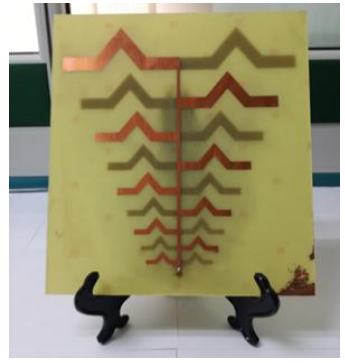

(b)

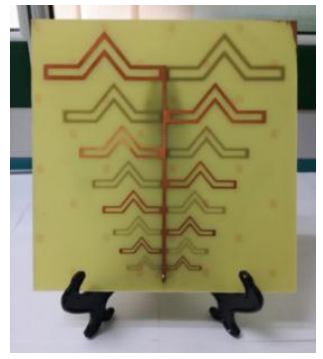

(c)

Figure 4. Fabricated antenna design; (a) $0^{\text {th }}$ iteration, (b) $1^{\text {st }}$ iteration, (c) slotted $1^{\text {st }}$ iteration $\log$ periodic fractal Koch antenna

\section{RESULTS AND DISCUSSION}

The comparison of the simulated and measured results is explained in this section. The discussions are on the reflection coefficient (S11), radiation pattern and realized gain of the antenna design. Figure 5 shows the reflection coefficient of the antennas design for the $0^{\text {th }}$ iteration, $1^{\text {st }}$ iteration and slotted $1^{\text {st }}$ iteration. It can be observed that the the antenna has a good simulated reflection coefficient from $0.4 \mathrm{GHz}$ to $1.0 \mathrm{GHz}$. However, for the $1^{\text {st }}$ iteration, the lower frequency has been shifted to the right which correspond to $20 \%$ frequency shifting from the lower frequency of $0^{\text {th }}$ iteration. With the introduction of slot at each of the radiating elements and the ground plane, it widens the lower impedance bandwidth by $17 \%$ as compared to the $1^{\text {st }}$ iteration. The improvement of the bandwidth was calculated by using Equation (2) [19] where the initial bandwidth was based on the bandwidth of the $1^{\text {st }}$ iteration antenna.

$$
\% \text { Bandwidth improvement }=\frac{\text { New bandwidth-Initial bandwidth }}{\text { Initial bandwidth }}(100 \%)
$$

The antenna has a realized gain of more than $5 \mathrm{dBi}$ for the entire frequency as shown in Figure 6. The E-field and $\mathrm{H}$-field for two different frequencies at $0.5 \mathrm{GHz}$ and $0.9 \mathrm{GHz}$ are shown in Figure 7, Figure 8 and Figure 9 respectively. The corresponding antenna exhibits directional radiation pattern with a realized gain of more than $5 \mathrm{dBi}$. It has been proven that the antenna is functioning at the frequency of interest and subsequently will be used in UHF Digital TV antenna design. 


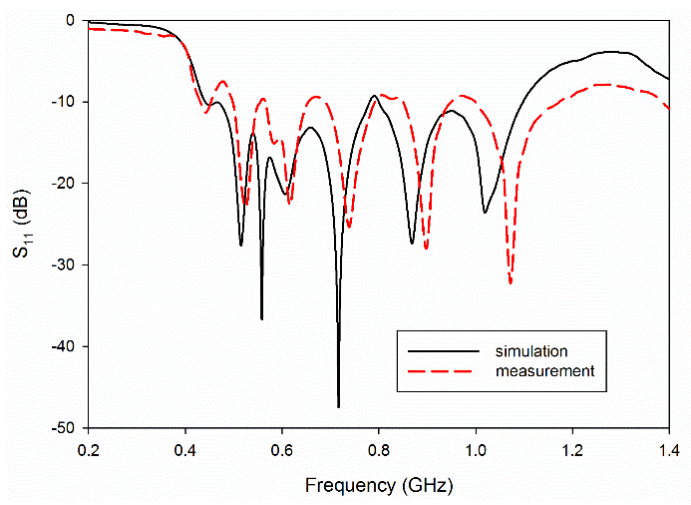

(a) $0^{\text {th }}$ iteration LPFKA

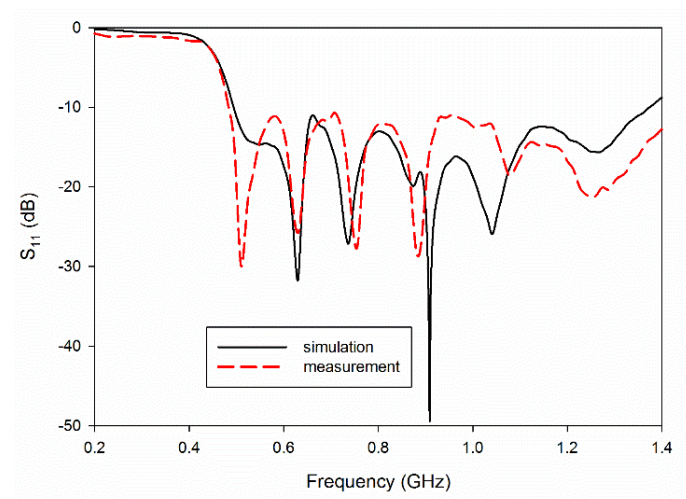

(b) $1^{\text {st }}$ iteration LPFKA

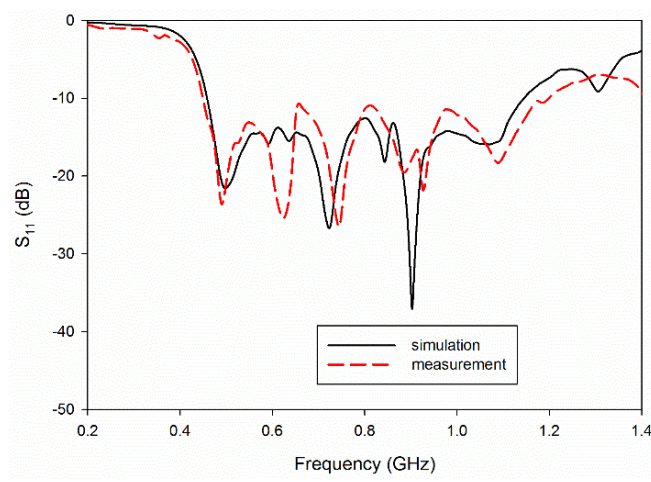

(c) Slotted $1^{\text {st }}$ iteration LPFKA

Figure 5. Simulated and measured results for antenna design

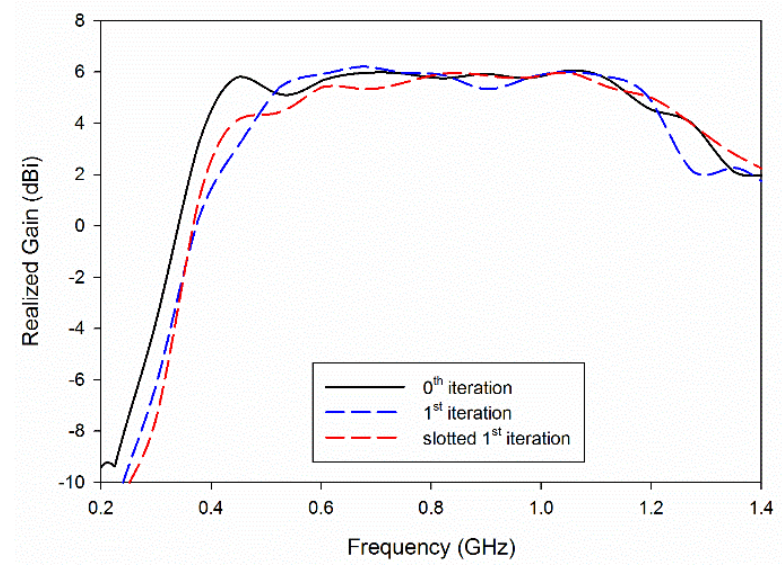

Figure 6. Simulated realized gain for the antenna design 


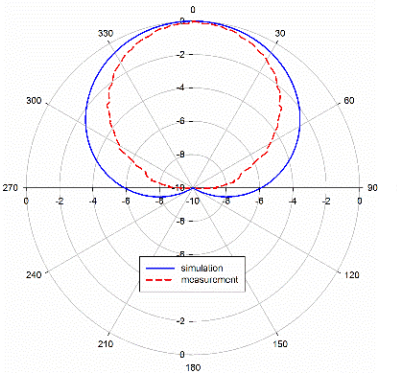

E plane

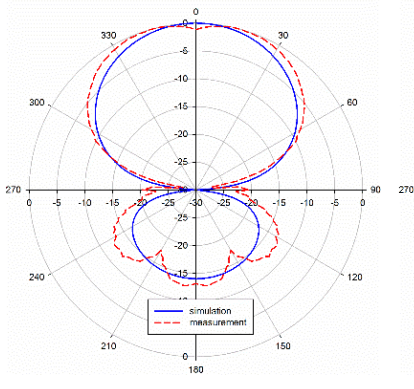

$\mathrm{H}$ plane

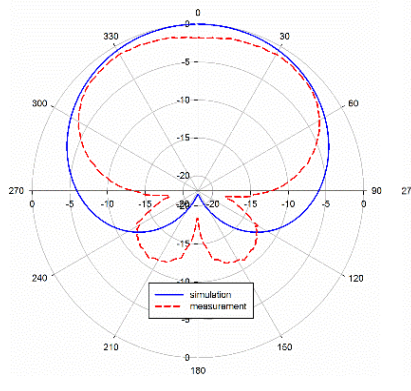

E plane

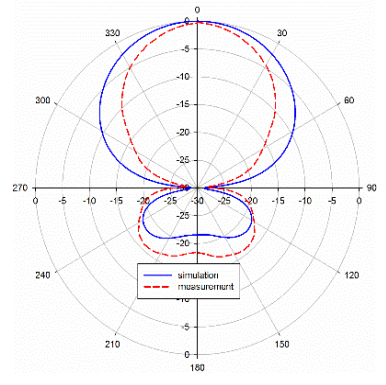

H plane

(a) $0.5 \mathrm{GHz}$

(b) $0.9 \mathrm{GHz}$

Figure 7. Simulated and measured radiation pattern for the $0^{\text {th }}$ iteration LPFKA

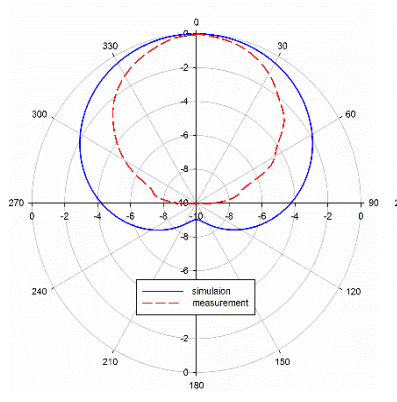

E plane

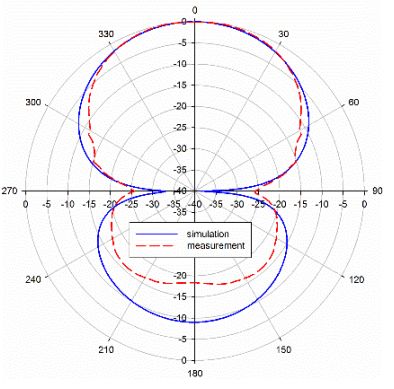

$\mathrm{H}$ plane

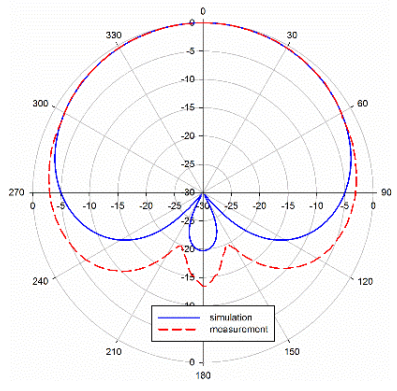

E plane

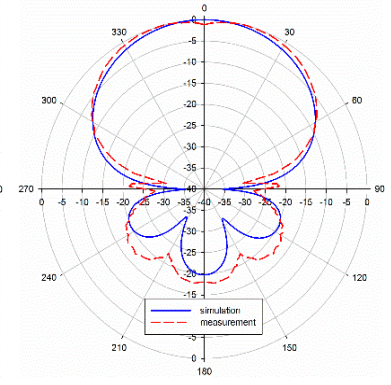

H plane

(a) $0.5 \mathrm{GHz}$

(b) $0.9 \mathrm{GHz}$

Figure 8. Simulated and measured radiation pattern for the $1^{\text {st }}$ iteration LPFKA

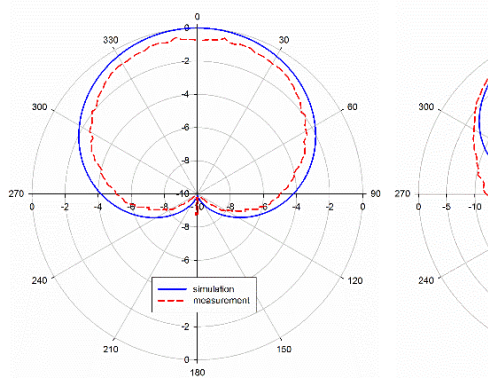

E plane

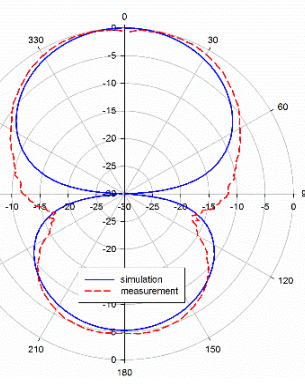

H plane

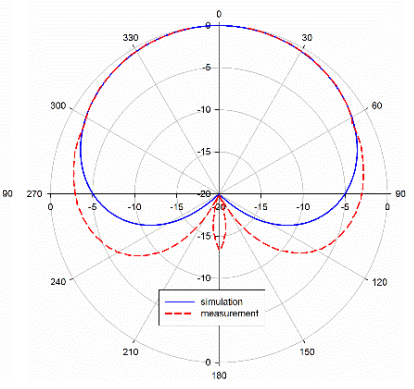

E plane

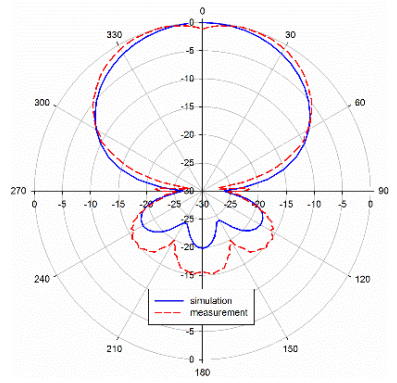

H plane

(a) $0.5 \mathrm{GHz}$

(b) $0.9 \mathrm{GHz}$

Figure 9. Simulated and measured radiation pattern for the slotted $1^{\text {st }}$ iteration LPFKA

\section{CONCLUSION}

The design of the Log Periodic Fractal Koch Antenna with $0^{\text {th }}$ iteration, $1^{\text {st }}$ iteration and slotted $1^{\text {st }}$ iteration have been designed, simulated, fabricated and measured. An antenna with a reduced size, high gain, and with the required bandwidth was elaborated. From the results, $17 \%$ of size reduction was achieved at slotted $1^{\text {st }}$ iteration for the fractal Koch method. The antennas have $\mathrm{S}_{11}<-10 \mathrm{~dB}$ bandwidth from $0.4 \mathrm{GHz}$ to 
1.0 GHz. The achievable gain was more than $5 \mathrm{dBi}$ for the entire frequency range of interest. Therefore, it shows that by applying the slot to the antenna design, the size of the antenna is successfully reduced. The performance of the antennas is maintained throughout the designated frequency range.

\section{ACKNOWLEDGEMENTS}

The authors thank the Ministry of Higher Education (MOHE) for supporting the research work; Research Management Centre (RMC), School of Postgraduate Studies (SPS), Communication Engineering Department, Faculty of Electrical Engineering (FKE), and Universiti Teknologi Malaysia (UTM) Johor Bahru for the support of the research under grant no 12H09, and 4F360.

\section{REFERENCES}

[1] T. O. L. Y. Alxtelvxas, "Log Periodic Dipole Arrays *," IRE Trans. ANTENNAS Propag., pp. 260-267, 1960.

[2] D. E. Anagnostou, J. Papapolymerou, S. Member, M. M. Tentzeris, S. Member, and C. G. Christodoulou, "A Printed Log-Periodic Koch-Dipole Array ( LPKDA )," IEEE Antenna Propag. Lett., vol. 7, pp. 456-460, 2008.

[3] W. Webb, "On Using White Space Spectrum,” IEEE Communications Magazine, pp. 145-151, 2012.

[4] J. Lee, J. Yeo, and Y.-K. Cho, "Broadband Compact Quasi-Yagi Antenna for Indoor Digital TV," Microw. Opt. Technol. Lett., vol. 55, pp. 2781-2784, 2013.

[5] O. T. . Chen and C. Tsai, "CPW-Fed Wideband Printed Dipole Antenna for Digital TV Applications," IEEE Trans. Antennas Propag., vol. 59, pp. 4826-4830, 2011.

[6] J. P. Gianvittorio and Y. Rahmat-Samii, "Fractal Antennas: A novel Antenna Miniaturization Technique, and Applications," IEEE Antennas Propag. Mag., vol. 44, pp. 20-36, 2002.

[7] G. A. Casula, P. Maxia, G. Montisci, G. Mazzarella, and F. Gaudiomonte, "A Printed LPDA Fed By A Coplanar Waveguide for Broadband Applications,” IEEE Antennas Wirel. Propag. Lett., vol. 12, pp. 1232-1235, 2013.

[8] B. B. Mandelbrot, The Fractal Geometry of Nature, vol. 51. 1983.

[9] N. A. A. Rahman, M. F. Jamlos, H. Lago, M. A. Jamlos, P. J. Soh, and A. A. Al-Hadi, "Reduced Size of SlottedFractal Koch Log-Periodic Antenna for 802.11af TVWS Application,” Microw. Opt. Technol. Lett., vol. 57, pp. 2781-2784, 2015.

[10] M. N. A. Karim, M. K. A. Rahim, H. A. Majid, O. Ayop, M. Abu, and F. Zubir, "Log Periodic Fractal Koch Antenna for UHF Band Applications," Prog. Electromagn. Res., vol. 100, pp. 201-218, 2010.

[11] S. R. Best and J. D. Morrow, "The Effectiveness of Space-Filling Fractal Geometry in Lowering Resonant Frequency," IEEE Antennas Wirel. Propag. Lett., vol. 1, pp. 112-115, 2002.

[12] A. Barcellos, "The Fractal Geometry of Mandelbrot," Coll. Math. J., vol. 15, pp. 98-114, 1984.

[13] S. Singh, P. K. Singhal, and V. V Thakare, "Design and Analysis of Tripple Band Koch Fractal Yagi Uda Antenna," Int. J. Electr. Comput. Eng., vol. 3, pp. 456-460, 2013.

[14] M. Ihamji, E. Abdelmounim, H. Bennis, M. Hefnawi, and M. Latrach, "Design of Compact Tri-Band Fractal Antenna for RFID Readers," Int. J. Electr. Comput. Eng., vol. 7, p. 2036, 2017.

[15] N. Wideband, P. Fractal, and M. Antenna, "Novel Wideband Planar Fractal Monopole Antenna," IEEE Trans. Antennas Propag., vol. 56, pp. 3844-3849, 2008.

[16] C. P. Baliarda, J. Romeu, and A. Cardama, "The Koch Monopole: A Small Fractal Antenna," IEEE Trans. Antennas Propag., vol. 48, pp. 1773-1781, 2000.

[17] R. Dakir, J. Zbitou, A. Mouhsen, A. Tribak, M. Latrach, and A. M. Sanchez, "A New Compact and Miniaturized GCPW-fed Slotted Rectangular antenna for Wideband UHF FIRD Applications," Int. J. Electr. Comput. Eng., vol. 7, p. 767, 2017.

[18] C. A. Balanis, Antenna Theory Analysis and Design Third Edition. 2005.

[19] R. Dewan, S. K. A. Rahim, S. F. Ausordin, and T. Purnamirza, "The Improvement of Array Antenna Performance with the Implementation of an Artificial Magnetic Conductor (Amc) Ground Plane and in-Phase Superstrate," Prog. Electromagn. Res., vol. 140, pp. 147-167, 2013.

\section{BIOGRAPHIES OF AUTHORS}

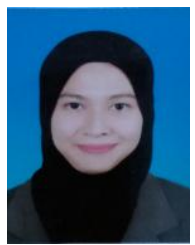

Nur Syahirah Mohd Yaziz received her B. Eng degree in Electrical Engineering (Telecommunication) from Universiti Teknologi Malaysia in 2015. She currently pusuiding her M. Eng. Degree in Electrical Engineering in Universiti Teknologi Malaysia. Her research interest is in antenna designs. 


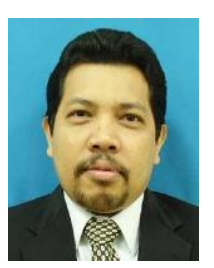

Mohamad Kamal A. Rahim received the B Eng. degree in Electrical and Electronic Engineering from University of Strathclyde, UK, in 1987. In 1989, he joined the Department of Communication Engineering, Faculty of Electrical Engineering Universiti Teknologi Malaysia Kuala Lumpur as an Assistant Lecturer A. He obtained his M. Eng Science from University of New South Wales Australia in 1992 and PhD degrees in Electrical Engineering from University of Birmingham UK in 2003. After he received his Master he was appointed as a Lecturer at Faculty of Electrical Engineering. Now he is the Professor in RF and Antenna at Faculty of Electrical Engineering Universiti Teknologi Malaysia. Some of his research interest includes the areas of design of dielectric resonator antennas, microstrip antennas, RFID antennas for readers and tags, microwave circuits, EBG, artificial magnetic conductors, metamaterials, phased array antennas, computer aided design for antennas, and design of millimeter frequency antennas. He has published over 200 articles in journals and conference papers.

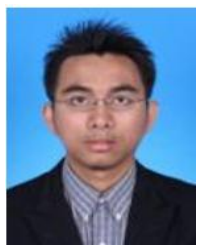

Farid Zubir received his first degree in Electrical Engineering (Telecommunication) from Universiti Teknologi Malaysia in 2008. In 2010, he received his M. Eng. Degree (Communication) from the same university and was awarded Best Postgraduate in the Faculty of Electrical Engineering as well as certified by the University's Senate for Pro-Chancellor Award at the graduation ceremony. He completed his PhD at the University of Birmingham for research into the direct integration of power amplifiers with antennas in microwave transmitters in 2016. His current research interest and specialization are in the area of RF and Microwave technologies including Planar Array Antenna, Dielectric Resonator Antennas (DRAs), Active Integrated Antenna (AIA), Microstrip Reflectarray Antenna (MRA), Electromagnetic Band Gap (EBG), Artificial Magnetic Conductor (AMC), Full-integrated Transmitting Amplifiers, Linear PAs, Doherty PAs and Bias Decoupling Circuits.

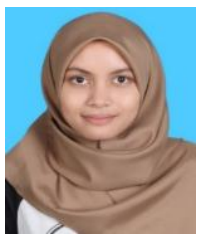

Norsaidah Muhamad Nadzir received her B. Eng. degree in Electrical Engineering (Computer Engineering) from Universiti Teknologi Malaysia in 2016. She is currently pursuing her M. Eng. degree in Electrical Engineering in Universiti Teknologi Malaysia. Her research interest includes RFID antennas for readers and tags, computer aided design for antennas, small antennas, computer systems, and wireless sensor networks.

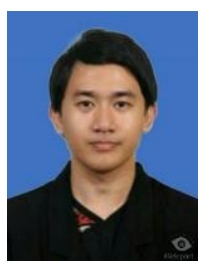

Raimi Dewan received his Bachelor Degree and Master Degree in Telecommunication Engineering from Universiti Teknologi Malaysia (UTM) in 2010 and 2013 respectively. Currently he is a postgraduate student at the same university. His research interest is in antenna designs.

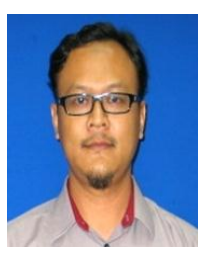

Huda A Majid received the B. Eng. Degree in Electrical Engineering (Telecommunication) from Universiti Teknologi Malaysia, in 2007. He then obtained his M. Eng. in 2010 and PhD degrees in Electrical Engineering in 2013, at Universiti Teknologi Malaysia. He is currently a lecturer in the department of Electrical Engineering Technology, Faculty of Engineering Technology, Universiti Tun Hussein Onn Malaysia. His research interest includes the area of design of microstrip antennas, small antennas, reconfigurable antennas, metamaterial antennas, metalatterial antennas, and millimeter wave antennas. He has published over 50 articles in journals and conference papers. 